\title{
Suicide Terrorism and the Weakest Link
}

\author{
DANIEL G. ARCE \\ DAN KOVENOCK \\ BRIAN ROBERSON
}

CESIFO WORKING PAPER NO. 2753

Category 2: Public Choice

August 2009

\footnotetext{
An electronic version of the paper may be downloaded

- from the SSRN website:

- from the RePEc website:

- from the CESifo website:

www.SSRN.com

Www.RePEc.org

www.CESifo-group.org/wp
} 


\title{
Suicide Terrorism and the Weakest Link
}

\begin{abstract}
In this paper we examine a model of terrorism which focuses on the tradeoffs facing a terrorist organization that has the ability to utilize either or both suicide and conventional terrorism tactics. The terrorist organization's objective is to successfully attack at least one target. Success for the target government is defined as defending all targets from any and all attacks. In this context, we examine how terrorist entities strategically utilize suicide attacks when other modes of attack are available, and the optimal anti-terrorism measures.
\end{abstract}

JEL Code: C70, D74.

Keywords: conflict, suicide terrorism, weakest link, Colonel Blotto.

\author{
Daniel G. Arce \\ University of Texas at Dallas \\ GR31, Department of Economics \\ School of Economic, Political and Policy \\ Sciences \\ 800 W. Campbell Rd \\ USA - Richardson, TX 75080 \\ darce@utdallas.edu
}

\author{
Dan Kovenock \\ University of Iowa \\ Department of Economics \\ Tippie College of Business \\ W284 PBB \\ 21 E. Market Street \\ USA -Iowa City, IA 52242 \\ dan-kovenock@uiowa.edu
}

\author{
Brian Roberson \\ Miami University \\ Department of Economics \\ 3108 Farmer School of Business \\ USA - Oxford, OH 45056 \\ robersba@muohio.edu
}

Part of this work was completed while Kovenock was Visiting Professor at the Social Science Research Center Berlin (WZB). 


\section{Introduction}

Terrorism is a form of asymmetric conflict in which terrorists utilize violent actions against (mainly civilian) noncombatants in order to influence a target audience beyond the immediate victims and, ultimately, to obtain ideological, political or religious objectives. Whereas terrorism is asymmetric in that terrorist groups have a relative resource disadvantage with respect to the target government, there also exist structural asymmetries between attack and defense which terrorists can turn to their advantage through their selection of targets and tactics. For example, governments with high-profile counterterror policies (e.g., the war on terror), or those facing a coordinated terrorist campaign (e.g., the French in Algeria) are often judged by their ability to deter or interdict all attacks. As is written in the Joint House-Senate Intelligence Inquiry into September 11, 2001 (US Congress, 2002), terrorists need to be successful only once to kill Americans and demonstrate the inherent vulnerabilities they face. This suggests that, as a whole, the set of targets of interest to terrorist groups may be viewed as a weakest-link network from the perspective of a target government. Our point is that in addition to the traditional treatment of terrorism-as-asymmetric-conflict in terms of the relative resource disparity between terrorists and their ultimate targets, an additional asymmetry exists through the definition of success. For the target government, success is defined in terms of security against all possible attacks; whereas for terrorists one success is often enough to alter the political landscape, airways, etc. If one target is successfully attacked, then counterterror policy and the competency of the government itself can be subject to public scrutiny. Success for the terrorist can mean (total) failure for the state, no matter how many prior terror attempts have been foiled. Moreover, at the target level, the breach of an interdependent network for airline travel or an oil pipeline can disrupt much (if not all) of the entire system. In this way, there are sound reasons for examining counterterror policy and terrorist tactics from the perspective of defending weakest links.

The term weakest link stems from Hirshleifer's (1983) metaphor about the public good provided by dike builders on the perimeter of a circular island (c.f. Cornes 1993, Hausken 2002). Whoever builds the lowest dike will define the entire island's level of defense against a flood. For target governments facing a terrorist campaign, the threat can be just as unrelenting as a rising sea, probing for a weak point that highlights their target's susceptibility. For example, after bombing the Brighton hotel where Margaret Thatcher was staying in the 1980s, and failing to kill her, the IRA issued a statement. It read: 'Today you have been lucky. But you have to be lucky every time. We only have to be lucky once,' (King 2008). Furthermore, when the vulnerability of one target not only depends on its choice of security 
measures, but also on the actions of others, a situation of interdependent security can arise that is consistent with a weakest link. Heal and Kunreuther (2005) give the example of airline baggage screening. Specifically, the 1988 crash of Pan Am 103 over Lockerbie, Scotland was due to a bomb that was contained in a bag initially screened by Malta Airlines in Malta, thereby constituting the weak link.

In addition, just as a wave may crest at the right moment to break the dike, terrorists have an additional tactic at their disposal. Suicide terrorism, which accounts for an average of twelve times more damage than conventional attacks (Sandler et al 2008), has increased in recent years (Economist 2008). The modern use of this tactic dates to the 1983 Beirut bombings by Hezbollah against US and French military personnel, with the bombings being viewed as bringing about these nations' troop withdrawals from Lebanon. This tactic was subsequently adopted by the Tamil Tigers (LTTE) and Kurdistan Workers' Party (PKK), and has been indelibly ingrained into the American psyche subsequent to the mass casualty suicide attacks of September 11, 2001 (called 9/11 hereafter). Yet no group that employs suicide terror does so exclusively (Crenshaw 2007). For example, the 3 March 2004 train station bombings in Madrid are associated with affiliates of al-Qaeda, but it was not a suicide operation, as the bombs were left on trains. ${ }^{1}$ Indeed, the use of cell phones as detonators in the Madrid bombings is one rationale for why the Aznar government initially suspected that the Basque organization Euskadi ta Askatasuna (ETA) was behind the attacks, as this form of detonation was a signature of past ETA attacks. Moreover, prior to the bombings the Aznar government was favored to easily win the elections that were scheduled three days hence. Instead, it lost; a result that is widely interpreted as stemming from electoral accountability in the aftermath of the bombings. For the al-Qaeda organization and its affiliates alone, the 1993 World Trade Center bombing; the 29 May 2004 Al-Khobar massacres in Saudi Arabia; and the 30 June 2007 discovery of explosives found in unattended cars parked at Piccadilly Circus and Trafalgar Square are additional examples of non-suicide attacks.

Crenshaw (2007) provides a review of thirteen books on the subject of suicide terrorism/martyrdom, all of which were published post-9/11, and deal almost exclusively with suicide bombing from the perspective of the bomber/operative. Yet both Hoffman and McCormick (2004) and Crenshaw (2007) recognize that suicide actions are rational for the group that operatives represent, and that explaining how suicide tactics fit into the groups' overall strategy of violence is remarkably understudied. ${ }^{2}$ The purpose of this paper is to examine

\footnotetext{
${ }^{1}$ The suspects blew themselves up later to avoid capture.

${ }^{2}$ In her review, Crenshaw (2007) concludes that there is no longer any need to introduce an analysis of suicide attacks by explaining to the uninitiated that it is not rooted in psychopathology or fanaticism or
} 
and characterize - in the context of a weakest-link network - how terrorist entities strategically utilize suicide attacks when other modes of attack are available. As discussed above, the weakest-link viewpoint may be due to the policymakers' (or voters') perception that successful counterterror policy involves the complete absence of incidents within a defined protectorate (e.g., Gassebner et al 2008, King 2008, Rosenbaum 2008), or the target itself may be a network corresponding to a weakest-link technology, as is the case with inter-airline baggage handling or critical infrastructure. Under either interpretation there is a structural asymmetry in the terrorist's favor. In addition, suicide attacks are, on average, far more severe than conventional attacks, and the severity of attack has been shown to increase the likelihood of cabinet changes within a government (Gassebner et al 2008).

In this paper we examine a model of terrorism which introduces a suicide attack technology that augments terrorist organizations' ability to allocate conventional resources. Therefore our focus is not on the rationality of suicide operatives, but on the tradeoffs facing a terrorist organization that has the ability to utilize either or both suicide terrorism tactics and conventional tactics. In equilibrium, we find that: (i) the terrorist organization may choose with positive probability not to launch any attacks, (ii) in the case that an attack is launched at most one target is attacked, and (iii) conditional on an attack being launched the suicide attack technology is not utilized with probability one. Remarkably, we find that the frequency and magnitude of suicide attacks depends on a simple measure that incorporates the structural asymmetry arising in the weakest-link network and the asymmetry between the characteristics of both the attacker and the defender which we term the normalized relative strength of the attacker. As the normalized relative strength of the attacker approaches unity the conflict becomes more symmetric, and the equilibrium frequency and magnitude of suicide attacks increases. In addition we find that the incidence of suicide terrorism increases as the total cost of utilizing suicide operatives decreases. Given that this total cost includes the costs of recruiting and training suicide operatives as well as the final force expenditure, our model is consistent with the stylized fact that suicide terrorism is likely to arise in an environment in which a group has significant political support (i.e., lower costs of recruitment) but not the means for political expression (Hoffman and McCormick 2004).

In examining suicide terrorism, our analysis highlights two critical features: (i) weakestlink networks of targets and (ii) the availability of both conventional and suicide tactics for the attacker. Weakest-link networks inherently possess an aggregate interdependence among targets that fundamentally differs from traditional models of strategic resource allocation.

indeed in any single cause such as deprivation, religious belief, or frustration (p.162). 
For example, in the classic Colonel Blotto game ${ }^{3}$ each target is won by the player who allocates the higher level of force and the payoff to each player is the sum of the wins across the entire set of targets, much as the level of a public good that is voluntarily provided is most often taken to be the sum over individual contributions. By contrast, in our study both the government's (defender's) and terrorists' (attackers') payoffs are a function of the minimum over the outcomes at each target, rather than the sum of the outcomes at each target. ${ }^{4}$ Additionally, owing to the fact that there is a positive opportunity cost of resource expenditure, the game which we examine here is not zero-sum.

Examinations of the min aggregator/weakest-link defense technology include Clark and Konrad (2007), Hausken (2008), and Kovenock and Roberson (2008); however, these models restrict the attacker to only the conventional allocation of homogenous resources across targets. In our study, the technology of attack allows for both the continuous allocation of conventional resources across targets and also a discrete resource — suicide operatives — that can be used in combination with a conventional attack, or entirely apart from conventional resources. This allows us to characterize how and why terrorist organizations choose their mix of conventional and suicide attacks, as those organizations that have suicide operatives at the ready do not rely exclusively on suicide attacks.

The paper proceeds as follows. In section 2 we describe a model of conflict with technologies of attack and defense in terms of the players, their strategies, and payoffs. In section 3 the model is solved with the result being a mixed strategy Nash equilibrium. This characterization is consistent with the observation that suicide terrorism is not the exclusive modus operandi of the way in which terrorists broaden the impact of their actions by creating an aura of uncertainty through tactics that appear to be random. In particular, we are able to characterize the frequency of suicide attacks and the nature of terrorist "spectaculars," whether of the suicide or conventional variety. The final section contains brief concluding remarks.

\footnotetext{
${ }^{3}$ See for example Borel (1921), Gross and Wagner (1950), Roberson (2006), Kvasov (2007), Golman and Page (2008), Hart (2008), or Roberson and Kvasov (2008).

${ }^{4}$ Alternative analyses of the macrotechnologies of conflict for target governments include defensive versus proactive/preemptive measures (Arce and Sandler 2005) and disruptive versus defensive tactics (Franck and Melese 2004).
} 


\section{The Model}

\section{Players and Strategies}

We examine a complete-information, simultaneous-move, one-shot game in which two players, an attacker, $A$, and a defender, $D$, allocate their forces across a weakest-link network consisting of a finite number, $n \geq 2$, of homogenous targets. Each player chooses a level of a continuous (conventional) one-dimensional force for each of the targets. For the defender this is the level of defensive force for each target; for the attacker this is the level of the conventional (non-suicide) force for each target. For both players conventional forces have a unit cost equal to one, and the level of conventional force allocated to each target must be nonnegative. In addition to a conventional attack, for each target $i$ the attacker has the opportunity to send a discrete number of suicide operatives denoted by $s_{i} \in\{0,1,2, \ldots\}$ (where $s_{i}=0$ denotes no suicide attack) at cost $c$ for each operative which provides an effective force allocation of $S$ for each operative. Let $\mathbf{s}=\left(s_{1}, s_{2}, \ldots, s_{n}\right)$ denote the $n$-tuple of the attacker's allocation of suicide operatives across the $n$ targets. To get the same effect as a suicide attack with conventional forces the attacker would have to allocate $S$ units of conventional forces to target $i$.

We focus on the case that the suicide attack is strongly efficient, $c<S$. For example, the improvised explosive devices worn or carried by a suicide bomber can cost less than $\$ 150$ to produce and the bombers themselves are regarded as expendable assets from the organizational perspective (Hoffman and McCormack 2004). On average, suicide terrorists produce more than they cost (Atran 2003). By contrast, although discrete, weapons of mass destruction (WMD) in the vein of chemical, biological and radio-nuclear (CBRN) attacks have yet to be proven to be cost efficient for terrorists relative to suicide or conventional attacks, due to the difficulties of procurement and weaponization of CBRN, and increased vulnerability to detection of WMD by intelligence services (Franck and Melese 2004). Furthermore, the requirements to be a successful suicide operative are not trivial, involving a level of intelligence that exceeds what is required of operatives in a conventional attack. ${ }^{5}$ The suicide attack technology captures the notion that a tactic such as a suicide attack is a discrete decision that, although cost effective, entails costs - including recruitment, training, and the final force expenditure. As Iannacconne (2006) observes, the number of "martyrs" is

\footnotetext{
${ }^{5}$ For example, Sageman (2004) finds that the suicide operatives of the global Salafist movement (which includes al-Qaeda) were far more educated than the average person worldwide, with $60 \%$ having college degrees
} 
very small relative to the total number of the members in the groups that employ suicide terrorism.

\section{Payoffs}

Our focus is on a weakest-link network of targets, and the players have asymmetric payoff functions reflecting the structural asymmetry arising in the weakest-link network. For each target, the player that allocates the higher level of force wins that target. In the case that the players allocate the same level of force to a target, the defender wins the target. For the defender success consists of allocating at least as high a level of force to all targets within the network. Conversely, an attacker is successful if he allocates a higher level of force to at least one target in the network.

For example, using Memorial Institute for the Prevention of Terrorism (MIPT) data, Gassebner et al (2008) find statistically significant evidence of a 'one strike and you're out' phenomenon whereby the presence of at least one terror event increases the likelihood of a cabinet change within a target government, with the likelihood of a change increasing with the severity of attack. Further, some targets themselves are, by definition, weakest links. The luggage transfer of the suitcase bomb that downed Pam Am flight 103 is an example, as is the interdiction of a twin car bombing plot against Saudi Arabia's main oil processing facility (Economist 2008). Similarly, pipeline attacks in Nigeria have had a significant impact on Nigerian oil production as well as on crude prices internationally.

For the defender, let $\mathbf{d}=\left(d_{1}, d_{2}, \ldots, d_{n}\right)$ denote an $n$-tuple of forces across the $n$ targets. Similarly, let $\mathbf{a}=\left(a_{1}, a_{2}, \ldots, a_{n}\right)$ denote an $n$-tuple of the attacker's conventional forces, where $a_{i}$ denotes the attacker's allocation of conventional force to target $i$. Recall that $\mathbf{s}=\left(s_{1}, s_{2}, \ldots, s_{n}\right)$ denotes the attacker's $n$-tuple of suicide operatives. Given that the attacker may utilize either or both conventional or suicide tactics, we define the attacker's effective force allocation as follows

Definition 1. The attacker's effective force allocation for target $i$ is the sum of the attacker's allocation of the continuous conventional resource to target $i$ and the force of any and all suicide operatives allocated to target $i$ :

$$
\hat{a}_{i}=a_{i}+S s_{i}
$$

where the $n$-tuple of the attacker's effective force allocations is denoted by $\hat{\mathbf{a}}$. 
Observe that if the attacker has chosen an effective force level of $\hat{a}_{i}$ for target $i$ such that $S \leq \hat{a}_{i}<2 S$, it is clearly cost minimizing for the attacker to set $s_{i}=1$. Similarly, given an effective force level of $\hat{a}_{i}$ for target $i$ such that $\lambda S \leq \hat{a}_{i}<(\lambda+1) S$ for some integer $\lambda$, an optimizing attacker has implicitly chosen $s_{i}=\lambda$. Note that any effective force level of $\hat{a}_{i}$ such that $\lambda S+c<\hat{a}_{i}<(\lambda+1) S$ is provided at the lowest cost by employing $\lambda$ suicide operatives and $\hat{a}_{i}-\lambda S$ units of conventional forces. However, the lowest cost of this effective force level is $\hat{a}_{i}-\lambda(S-c)$, which is greater than the cost of employing $\lambda+1$ suicide operatives, attaining an effective force level of $(\lambda+1) S>\hat{a}_{i}$. Consequently, no effective force allocation $\hat{a}_{i}$ such that $\lambda S+c<\hat{a}_{i}<(\lambda+1) S$ will be optimally employed by the attacker.

Success for the attacker is formally defined as follows.

Definition 2. The weakest-link indicator function, denoted by $\iota^{W L}$, takes a value of one if there exists a target $i$ for which the attacker's effective force (i.e., the conventional force plus the force from any and all suicide operatives) exceeds the defensive forces allocated to that target and takes a value of zero otherwise.

$$
\iota^{W L}= \begin{cases}1 & \text { if } \exists i \mid \hat{a}_{i}>d_{i} \\ 0 & \text { otherwise }\end{cases}
$$

In the event that all targets are successfully defended, the weakest-link indicator function takes a value of zero, but if any single attack is successful this indicator takes a value of one. Again, this corresponds to a 'one strike and you're out' implication for an incumbent target government (Gassebner et al 2008, Rosenbaum 2008). It also refers to the terrorist's need to only be lucky once in order to highlight the government's vulnerability (King 2008). Alternatively, a collection of specific targets (e.g., critical infrastructure) may intrinsically exhibit a weakest-link network structure.

The attacker's (terrorist's) payoff function is given by

$$
\pi_{A}(\mathbf{a}, \mathbf{s}, \mathbf{d})=v_{A} \iota^{W L}-c \sum_{i=1}^{n} s_{i}-\sum_{i=1}^{n} a_{i} .
$$

When any target is successfully attacked, so that $\iota^{W L}=1$, the terrorist receives the value of a successful attack, $v_{A}$, less the cost of the suicide operatives (if any) at each target and the cost of a conventional attack (if any) at each target. If no target is successfully attacked these costs are still born by the terrorist. Also, we have normalized the per unit cost of a conventional attack to one so that $c$ represents the relative cost of a suicide operative. 
The defender's payoff function is given by

$$
\pi_{D}(\mathbf{a}, \mathbf{s}, \mathbf{d})=v_{D}\left(1-\iota^{W L}\right)-\sum_{i=1}^{n} d_{i} .
$$

As in an insurance policy, the defender always pays the cost of defense, $\sum_{i=1}^{n} d_{i}$. This is augmented by the value of a successful defense, $v_{D}$, when every target is successfully defended, thereby reflecting a weakest-link vulnerability.

Given that terrorism is a form of asymmetric conflict with respect to both the resource disparity and the structural externalities arising in the weakest-link network of targets, it will be useful to introduce a simple summary statistic which captures both of these forms of asymmetry. Recall that the floor function $\lfloor x\rfloor$ gives the largest integer less than or equal to $x$, and observe that $\left\lfloor\frac{v_{A}}{c}\right\rfloor$ is the maximum number of suicide operatives that the terrorist organization can profitably employ.

Note that the maximum profitable expenditure for the attacker (defender) is $v_{A}\left(v_{D}\right)$, which if used solely by conventional means, translates into a maximal effective force of $v_{A}$ $\left(v_{D}\right)$. However, terrorist organizations also have the ability to utilize suicide operatives. An allocation $\mathbf{s}$ of suicide operatives across the targets increases the effective force by $\sum_{i} s_{i} S$ at a cost of $\sum_{i} s_{i} c$, implying that the maximal effective force that can be allocated at a cost of $v_{A}$ is $v_{A}+\left\lfloor\frac{v_{A}}{c}\right\rfloor(S-c)$.

Definition 3. The normalized relative strength of the attacker, denoted by $\alpha$, is the ratio of $n$ times the attacker's maximal effective force allocation to the defender's maximal effective force allocation,

$$
\alpha=\frac{n\left(v_{A}+\left\lfloor\frac{v_{A}}{c}\right\rfloor(S-c)\right)}{v_{D}},
$$

where $\alpha<1$ implies that the attacker is relatively disadvantaged and $\alpha>1$ implies that the attacker is relatively advantaged. As $\alpha \rightarrow 1$ the situation becomes (relatively) symmetric.

The coefficient $n$ applies because under a weakest-link structure the target government must successfully defend all possible targets from potential attacks. Hence, for the defender the maximum profitable expenditure that may be allocated equally to all targets is $v_{D} / n$. If $\alpha<1$, the attacker is relatively disadvantaged, and the defender has the ability to profitably apply to all $n$ targets a level of force that is greater than the level the attacker can profitably apply to a single target. Conversely, if $\alpha>1$, then the attacker is relatively advantaged, and the defender does not have the ability to profitably apply to all $n$ targets a level of force that is greater than what the attacker can profitably apply to a single target. 
To capture the notion that terrorist organizations have a relative resource disadvantage with respect to the target government, we focus on the case that $v_{D}>v_{A}$. However, given the structural asymmetries arising in the weakest-link network of targets, the normalized relative strength of the attacker identifies whether or not the defender has the ability to allocate more defensive forces to all $n$ targets than the amount of effective force the attacker can allocate to any one target ( $\alpha<1$ and $\alpha>1$ respectively). Furthermore, as the normalized relative strength of the attacker approaches unity we will refer to the conflict as being more symmetric, where this symmetry takes into account both the resource and structural asymmetries.

In the next section we provide an equilibrium in our model in which the attacker creates an aura of uncertainty over the mode of attack, conventional and/or suicide, as well as the identity of the target to be attacked. Hence, the defender faces strategic uncertainty over both the method of attack and the identity of the target to be attacked.

\section{Suicide terrorism: equilibrium and characterization}

Note that in our formulation: (i) force expenditures are sunk, (ii) force expenditures have a positive opportunity cost and (iii) the player who allocates the higher level of force to a target wins that target with certainty. ${ }^{6}$ Consequently, if one player wins with certainty, then the other player's best response is the strategy vector $\mathbf{0}$, which minimizes cost in a losing effort. Then, the winner will reduce the winning force arbitrarily close to zero in order to reduce cost as well. But then, $\mathbf{0}$ is no longer a best reply to this strategy. It clearly follows that there is no pure strategy equilibrium for this class of games.

Let $\mathbf{x}$ denote a generic $n$-tuple of (effective) forces. For the defender, a mixed strategy (which we term a distribution of force for the defender) is an $n$-variate distribution function $P_{D}: \mathbb{R}_{+}^{n} \rightarrow[0,1]$, where $P_{D}(\mathbf{x})=\operatorname{Pr}\left\{d_{i} \leq x_{i}\right.$ for all $\left.i\right\}$ denotes the probability that each $d_{i}$ in a random $n$-tuple $\mathbf{d}$ drawn from the $n$-variate distribution function $P_{D}$ is less than or equal to the corresponding $x_{i}$ in the $n$-tuple $\mathbf{x} \in \mathbb{R}_{+}^{n}$. Note that the univariate marginal distribution of $P_{D}$ for the $i$ th target, $F_{D}^{i}\left(x_{i}\right)=\operatorname{Pr}\left\{d_{i} \leq x_{i}\right\}$, denotes the probability that at target $i$ the level of force $d_{i}$ is less than or equal to $x_{i}$.

For the attacker, a pure strategy is a $2 n$-tuple consisting of the $n$-tuple of the attacker's allocation of the continuous resource across the $n$ targets and the $n$-tuple of the attacker's

\footnotetext{
${ }^{6}$ More formally, the conflict at each target utilizes the deterministic auction contest success function. See Baye, et al. (1996).
} 
allocation of suicide operatives across the $n$ targets. It follows directly that our focus on the attacker's effective force allocation does not place any restrictions on the correlation structures available to the attacker. To simplify the following expressions we will focus on the attacker's effective force allocation.

A mixed strategy for the attacker (which we term a distribution of effective force for the attacker) may thus be written as an $n$-variate distribution function $\hat{P}_{A}: \mathbb{R}_{+}^{n} \rightarrow[0,1]$, where $\hat{P}_{A}(\mathbf{x})=\operatorname{Pr}\left\{\hat{a}_{i} \leq x_{i}\right.$ for all $\left.i\right\}$ denotes the probability that the $n$-tuple of forces $\mathbf{x} \in \mathbb{R}_{+}^{n}$ successfully defends each and every target $i$ from attack given that the attacker's effective allocation of force across the $n$ targets, $\hat{\mathbf{a}}$, is a random $n$-tuple drawn from the $n$-variate distribution function $\hat{P}_{A}$.

Below we examine an equilibrium for all parameter configurations in which neither the suicide attack technology is prohibitively costly for the attacker $\left(v_{A} \leq c\right)$ nor the defender is so weak that suicide tactics are always suboptimal for the attacker $\left(\frac{v_{D}}{n}<c\right)$. The remaining cases, as well as the proof of our main theorem, are included in the appendix.

Recall that if there exists an integer $\lambda$ such that $\lambda S \leq \hat{a}_{i}<(\lambda+1) S$, then an optimizing attacker has implicitly chosen $s_{i}=\lambda$. In the analysis that follows it will also be helpful to define the following two functions, for $\mathbf{x}, \hat{\mathbf{x}} \in\left[0,\left(\left\lfloor\frac{v_{A}}{c}\right\rfloor+1\right) S\right]^{n}$ and $\lambda=0, \ldots,\left\lfloor\frac{v_{A}}{c}\right\rfloor$

$$
g\left(x_{i}\right)= \begin{cases}x_{i}-\lambda(S-c) & \text { if } \lambda S \leq x_{i}<\lambda S+c \\ (\lambda+1) c & \text { if } \lambda S+c \leq x_{i}<(\lambda+1) S\end{cases}
$$

and

$$
h\left(\hat{x}_{i}\right)=\left\{\begin{array}{ll}
\hat{x}_{i} & \text { if } \lambda S \leq \hat{x}_{i}<\lambda S+c \\
\lambda S+c & \text { if } \lambda S+c \leq \hat{x}_{i}<(\lambda+1) S
\end{array} .\right.
$$

To interpret $g\left(x_{i}\right)$ and $h\left(\hat{x}_{i}\right)$ note that it is suboptimal for a cost-minimizing attacker to allocate an effective force of $\hat{x}_{i} \in(\lambda S+c,(\lambda+1) S)$ for any integer $\lambda=0, \ldots,\left\lfloor\frac{v_{A}}{c}\right\rfloor$ [doing so is strictly dominated by the effective force $\hat{x}_{i}=(\lambda+1) S$ ]. For the defender, this suboptimal region corresponds to force allocations $x_{i} \in(\lambda S+c,(\lambda+1) S)$ for any integer $\lambda=0, \ldots,\left\lfloor\frac{v_{A}}{c}\right\rfloor$. Over the set of attacker's cost-minimizing effective force levels and the corresponding defensive force levels [i.e., $\hat{x}_{i}, x_{i} \in[\lambda S, \lambda S+c]$ for any integer $\left.\lambda=0, \ldots,\left\lfloor\frac{v_{A}}{c}\right\rfloor\right]$, the functions $g\left(x_{i}\right)$ and $h\left(\hat{x}_{i}\right)$ identify the attacker's minimal cost for allocating an effective force equal to $x_{i}$ units of defensive force and the defender's minimal cost for allocating force equal to $\hat{x}_{i}$ units of effective attack force, respectively. For $\hat{x}_{i}, x_{i} \in(\lambda S+c,(\lambda+1) S)$, the function $g\left(x_{i}\right)$ is completed by inserting the attacker's cost of effective force allocation at the 
upper endpoint of the interval, where $\lambda+1$ suicide operatives are employed, and the function $h\left(\hat{x}_{i}\right)$ is completed by inserting the defender's cost of force allocation at the lower endpoint of the interval.

Theorem 1. A Nash equilibrium of the model of terrorism with suicide attack is for each player to allocate his forces as follows.

(a) If $\alpha<1$, then for player $D$ and $\boldsymbol{x} \in\left[0, v_{A}+\left\lfloor\frac{v_{A}}{c}\right\rfloor(S-c)\right]^{n}$,

$$
P_{D}(\boldsymbol{x})=\frac{\min _{i}\left\{g\left(x_{i}\right)\right\}}{v_{A}}
$$

Similarly for player $A$ and $\hat{\boldsymbol{x}} \in\left[0, v_{A}+\left\lfloor\frac{v_{A}}{c}\right\rfloor(S-c)\right]^{n}$,

$$
\hat{P}_{A}(\hat{\boldsymbol{x}})=1-\alpha+\frac{\sum_{i} h\left(\hat{x}_{i}\right)}{v_{D}}
$$

The expected payoff for player $A$ is 0 , and the expected payoff for player $D$ is $v_{D}(1-\alpha)$.

(b) For $\alpha \geq 1$ and $c \leq\left(v_{D} / n\right)$, let $\bar{\lambda}$ be the largest nonnegative integer such that $\bar{\lambda} S<\frac{v_{D}}{n}$.

(i) If $\bar{\lambda} S<\frac{v_{D}}{n}<\bar{\lambda} S+c$, then for player $D$ and $\boldsymbol{x} \in\left[0,\left(v_{D} / n\right)\right]^{n}$,

$$
P_{D}(\boldsymbol{x})=1-\frac{\left(v_{D} / n\right)-\bar{\lambda}(S-c)}{v_{A}}+\frac{\min _{i}\left\{g\left(x_{i}\right)\right\}}{v_{A}}
$$

Similarly for player $A$ and $\hat{\boldsymbol{x}} \in\left[0,\left(v_{D} / n\right)\right]^{n}$,

$$
\hat{P}_{A}(\hat{\boldsymbol{x}})=\frac{\sum_{i} h\left(\hat{x}_{i}\right)}{v_{D}}
$$

The expected payoff for player $A$ is $v_{A}-\left(v_{D} / n\right)+\bar{\lambda}(S-c)$, and the expected payoff for player $D$ is 0 .

(ii) If $\bar{\lambda} S+c \leq \frac{v_{D}}{n} \leq(\bar{\lambda}+1) S$, then for player $D$ and $\boldsymbol{x} \in[0, \bar{\lambda} S+c]^{n}$,

$$
P_{D}(\boldsymbol{x})=1-\frac{(\bar{\lambda}+1) c}{v_{A}}+\frac{\min _{i}\left\{g\left(x_{i}\right)\right\}}{v_{A}}
$$


Similarly for player $A$ and $\hat{\boldsymbol{x}} \in[0,(\bar{\lambda}+1) S]^{n}$,

$$
\hat{P}_{A}(\hat{\boldsymbol{x}})=\frac{\sum_{i}\left[\min \left\{h\left(\hat{x}_{i}\right), \frac{v_{D}}{n}\right\}\right]}{v_{D}}
$$

The expected payoff for player $A$ is $v_{A}-(\bar{\lambda}+1) c$, and the expected payoff for player $D$ is 0 .

Figure 1 provides the supports of the equilibrium distributions of effective force for case (a) of Theorem 1 with $\left\lfloor\frac{v_{A}}{c}\right\rfloor=2$ and only two targets in the weakest-link network $(n=2){ }^{7}$ In case (a), as in all cases, the attacker launches an attack on at most one target. Note also that in case (a), as in all cases, the defender's allocation of force has perfect positive correlation. One property of this correlation structure is that for any given level of force the probability that the attacker destroys at least one target is maximized if the attack is on a single target. As a result the attacker launches an attack on at most one target. When as in case (a) the normalized relative strength of the attacker is less than one, the attacker launches at most one attack and launches no attacks with probability $1-\alpha$. Figure 2 provides the supports of the equilibrium distributions of effective force for subcase (i) of case (b) of Theorem 1 with $\left\lfloor\frac{v_{A}}{c}\right\rfloor=2$ and only two targets in the weakest-link network $(n=2)$. In this case, the attacker launches exactly one attack with certainty. The equilibrium number of attacks is summarized in corollary 1.

Corollary 1. In cases (a) and (b) of Theorem 1, for any realization of his equilibrium strategy the attacker attacks at most one target. In any case (b) realization the attacker launches an attack on exactly one target. In case (a) the attacker's equilibrium strategy attacks a single target with probability $\alpha$, and launches no attacks with the remaining probability.

The proof of corollary 1 is contained in the proof of Theorem 1 given in the appendix. It is important to note that our formulation of attack and defense features endogenous entry and force expenditure decisions and allows for the players to use general correlation structures for force expenditures across the targets within the weakest-link network. ${ }^{8}$ In contrast, much of the existing literature [e.g. Azaiez and Bier (2007), Bier and Abhichandani (2003), Bier et al. (2005), Bier et al. (2007), Levitin and Ben-Haim (2008), and Rosendorff and Sandler (2004) among others] assumes that the number of terrorist attacks (which is usually set to

\footnotetext{
${ }^{7}$ Recall that the support of an $n$-variate distribution function $P$, is the complement of the union of all open sets of $\mathbb{R}^{n}$ with $P$-volume zero.

${ }^{8}$ See also Kovenock and Roberson (2008).
} 


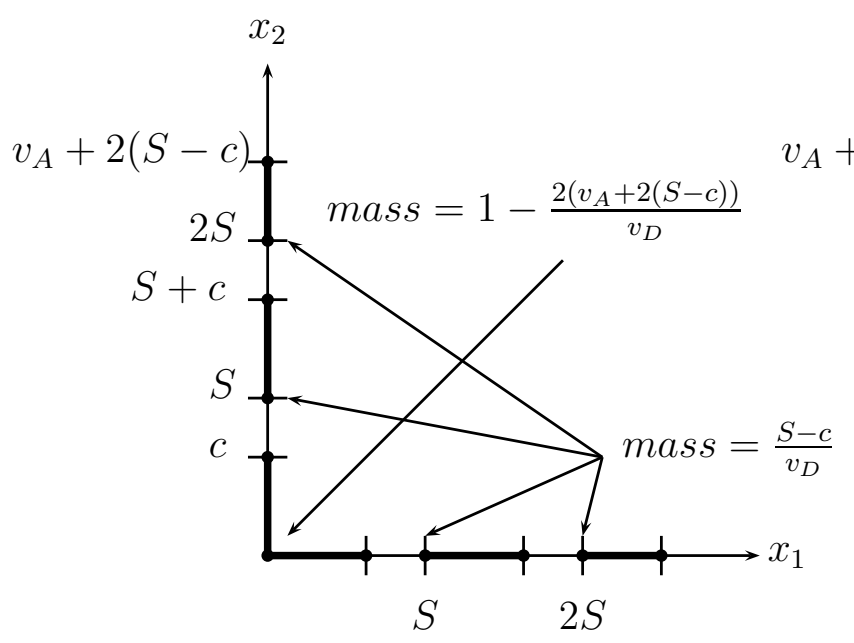

(i) Attacker

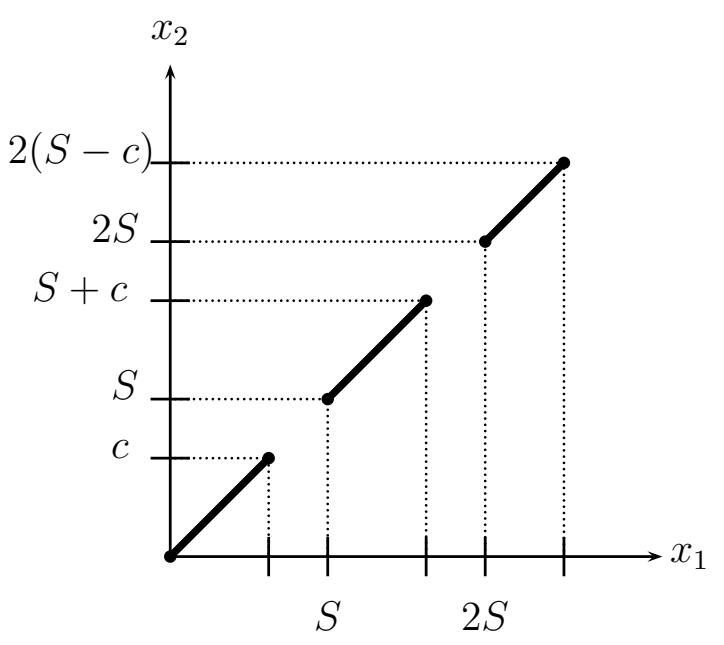

(ii) Defender

Figure 1: Supports of case (a) equilibrium joint distributions with $\left\lfloor\frac{v_{A}}{c}\right\rfloor=2$ and $n=2$.

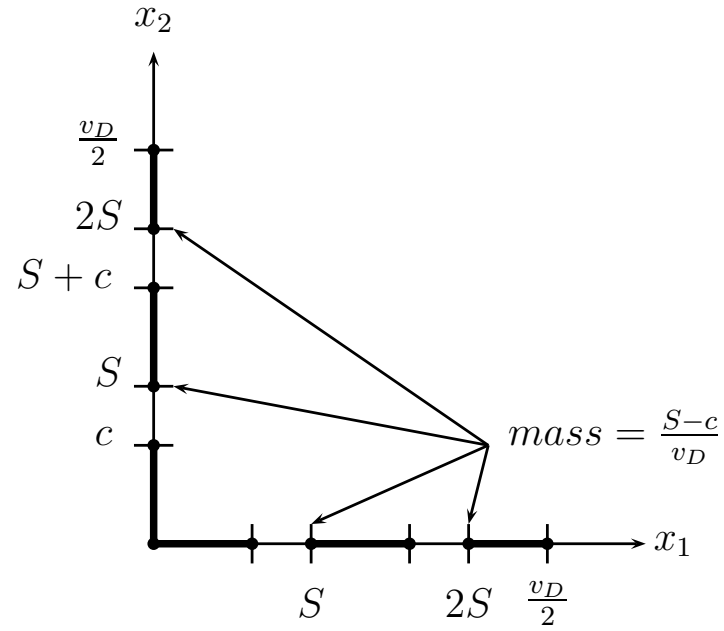

(i) Attacker

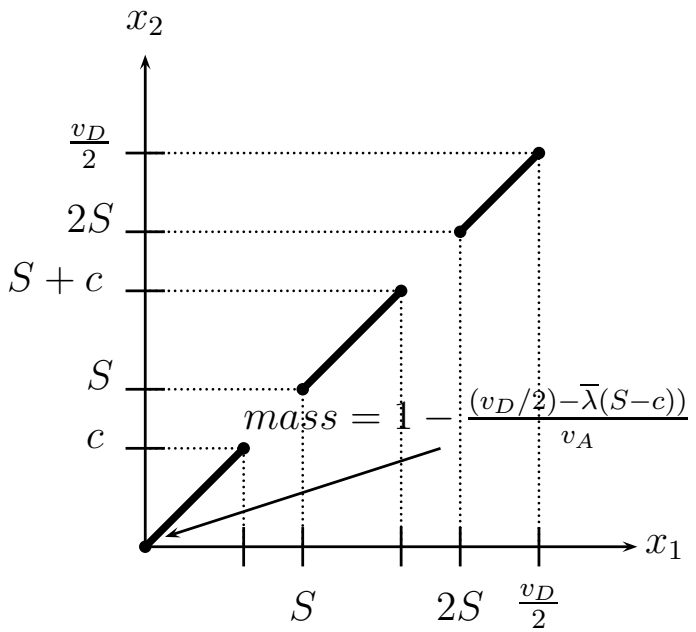

(ii) Defender

Figure 2: Supports of case (b), (i) equilibrium joint distributions with $\bar{\lambda}=2$ and $n=2$. 
one) is exogenously specified. Additionally, several of the existing models which allow for the attacker to endogenously choose the number of targets to attack ${ }^{9}$ obtain the paradoxical result, that even when (as in a weakest-link network) the attacker's objective is to destroy a single target, the attacker optimally chooses to attack every target with certainty. Conversely, we find that the attacker optimally chooses to attack at most one target, but each target is chosen with positive probability.

Given the endogenous number of targets that are attacked in the equilibrium given in Theorem 1, we now examine (i) the probability of a suicide attack conditional on an attack being made and (ii) the expected number of suicide operatives that are utilized conditional on a suicide attack being launched. Recall that if $\lambda S \leq \hat{a}_{i}<(\lambda+1) S$ then an optimizing attacker has implicitly set $s_{i}=\lambda$. Let $\mathbf{c}$ and $\mathbf{0}$ denote the $n$-tuples $(c, \ldots, c)$ and $(0, \ldots, 0)$, respectively. The conditional probability that the attacker launches at least one suicide attack is given by $\left(1-\hat{P}_{A}(\mathbf{c})\right) /\left(1-\hat{P}_{A}(\mathbf{0})\right)$, where $\hat{P}_{A}(\cdot)$ is player A's distribution of effective force. Recall that $\hat{P}_{A}(\mathbf{c})=\operatorname{Pr}\left\{\hat{a}_{i} \leq c\right.$ for all $\left.i\right\}$ is the probability that no attack exceeds level $c$ - and therefore does not require suicide operatives - and $1-\hat{P}_{A}(\mathbf{c})$ is the probability of at least one suicide attack. Similarly, $\hat{P}_{A}(\mathbf{0})$ is the probability of no attack and $1-\hat{P}_{A}(\mathbf{0})$ is the probability that at least one attack is made. In case (a), the conditional probability of suicide attack is $1-\left(c /\left(v_{A}+\left\lfloor\frac{v_{A}}{c}\right\rfloor(S-c)\right)\right)$. In case $(\mathrm{b})$, the conditional probability of suicide attack is $1-\left(n c / v_{D}\right)$. Although the upper bound of the number of equilibrium suicide operatives $\left\lfloor\frac{v_{A}}{c}\right\rfloor$ is not continuously differentiable with respect to $v_{A}$ and $c$, it follows that in cases (a) and (b) and for all marginal changes which hold $\left\lfloor\frac{v_{A}}{c}\right\rfloor$ constant - the conditional probability that the attacker utilizes a suicide attack is decreasing in the cost of a suicide operative $(c)$.

Recalling that the normalized relative strength of the attacker is the relevant measure of the symmetry of the conflict, consider two simple symmetry increasing transformations corresponding to the attacker having a normalized relative strength advantage and disadvantage repectively. The simple transformation for the case in which the attacker has a normalized relative strength disadvantage [case (a) of Theorem 1], which we term a cost invariant increase in the attacker's relative strength, corresponds to an increase in the expression $v_{A}+\left\lfloor\frac{v_{A}}{c}\right\rfloor S$, where again we focus on marginal changes which hold $\left\lfloor\frac{v_{A}}{c}\right\rfloor$ constant. ${ }^{10}$ In case (a) any simple transformation of this form results in an increase in the normalized rel-

\footnotetext{
${ }^{9}$ Most closely related is Clark and Konrad (2007) who, utilizing the Tullock contest success function, also examine a weakest-link network. See also Hausken (2008).

${ }^{10}$ This restriction allows for all marginal changes such that $S$ increases and/or $v_{A}$ increases, subject to $\left\lfloor\frac{v_{A}}{c}\right\rfloor$ remaining constant.
} 
ative strength of the attacker which approaches one from below. The simple transformation for the case in which the attacker has a normalized relative strength advantage [case (b) of Theorem 1], which we term a relative increase in the defender's strength, corresponds to an increase in the expression $\left(v_{D} / n\right)$. In case (b), a relative increase in the defender's strength leads to a decrease in the normalized relative strength of the attacker which approaches one from above.

In case (a) the normalized relative strength of the attacker is less than one, and for all cost invariant increases in the attacker's relative strength the conditional probability of suicide attack is increasing. Similarly, in case (b) the normalized relative strength of the attacker is greater than one, and for all relative increases in the defender's strength the conditional probability of suicide attack is increasing. That is, the more symmetric the conflict the more likely the attacker is to utilize suicide operatives when an attack is launched. These properties of the conditional probability of suicide attack are summarized in corollary 2.

Corollary 2. In cases (a) and (b) of Theorem 1, the conditional probability that the attacker utilizes at least one suicide operative is: (i) decreasing with respect to the cost of suicide operatives, and (ii) increasing with respect to our two simple symmetry increasing transformations of the environment.

The characterization above indicates that although terrorist organizations attack at most one target, suicide operations are not the exclusive modus operandi even when such operatives are available; the terrorist leadership randomizes over conventional and suicide tactics. For example, al-Qaeda has been associated with conventional (non-suicide) events such as the Madrid train station bombing, the Al-Khobar massacres in Saudi Arabia, and 2007 attempted car bombings of Piccadilly Circus and Trafalgar Square. As noted by Sandler et al (2008), terrorists broaden their audience beyond the immediate victim by making their attacks and tactics appear to be random, so that everyone feels at risk. Furthermore, the use of suicide operatives is an increasing function of the relative symmetry of terrorists and target governments. This is a novel insight given that the literature on terrorism almost exclusively emphasizes the resource asymmetry between target governments and terrorists but does not incorporate alternative technologies of attack or defense. Our measure of symmetry, $\alpha$, captures the potential for the weakest link technology to balance resource disparities. In particular, symmetry within a weakest-link framework leads to an increased likelihood of suicide attack.

Moreover, terrorist organizations not only randomize over the use of suicide and conventional tactics, but also the level of effective force. In the case of a suicide attack this involves 
randomization over the number of suicide operatives that are utilized. Recalling that the probability that the attacker launches a suicide attack is $1-\hat{P}_{A}(\mathbf{c})$, the case (a) expected number of suicide operatives conditional on a suicide attack being launched is

$$
\frac{\sum_{i=1}^{\left\lfloor\frac{v_{A}}{c}\right\rfloor-1} i\left(\hat{P}_{A}(\mathbf{i} \mathbf{S}+\mathbf{c})-\hat{P}_{A}((\mathbf{i}-\mathbf{1}) \mathbf{S}+\mathbf{c})\right)+\left\lfloor\frac{v_{A}}{c}\right\rfloor\left(1-\hat{P}_{A}\left(\left(\left\lfloor\frac{\mathbf{v} \mathbf{A}}{\mathbf{c}}\right\rfloor-\mathbf{1}\right) \mathbf{S}+\mathbf{c}\right)\right)}{1-\hat{P}_{A}(\mathbf{c})}
$$

where the term $\hat{P}_{A}(\mathbf{i S}+\mathbf{c})-\hat{P}_{A}((\mathbf{i}-\mathbf{1}) \mathbf{S}+\mathbf{c})$ is the probability that the attacker allocates exactly $i$ suicide operatives. In case (b) (i) [case (b) (ii)] the expected number of suicide operatives conditional on a suicide attack being launched is similarly calculated by replacing each $\left\lfloor\frac{v_{A}}{c}\right\rfloor$ in the above expression with $\bar{\lambda}[(\bar{\lambda}+1)]$. Table 1 provides the expected number of suicide operatives conditional on a suicide attack being launched in each of the three cases of Theorem 1.

\begin{tabular}{|c|c|}
\hline case (a) & $\left\lfloor\frac{v_{A}}{c}\right\rfloor-\left(\frac{\left\lfloor\frac{v_{A}}{c}\right\rfloor\left(\frac{\left\lfloor\frac{v_{A}}{c}\right\rfloor-1}{2}\right) S}{v_{A}+\left\lfloor\frac{v_{A}}{c}\right\rfloor(S-c)-c}\right)$ \\
\hline case (b) (i) & $\bar{\lambda}-\left(\frac{\bar{\lambda}\left(\frac{\bar{\lambda}-1}{2}\right) S}{\frac{v_{D}}{n}-c}\right)$ \\
\hline case (b) (ii) & $(\bar{\lambda}+1)-\left(\frac{\bar{\lambda}\left(\frac{\bar{\lambda}+1}{2}\right) S}{\frac{v D}{n}-c}\right)$ \\
\hline
\end{tabular}

Table 1: Expected number of suicide operatives conditional on the launch of a suicide attack

As was the case with the conditional probability that the attacker launches a suicide attack, the expected number of suicide operatives conditional on a suicide attack being launched is decreasing with respect to the cost of each suicide operative. Furthermore, in case (a) the expected number of suicide operatives conditional on a suicide attack being launched is increasing for all cost invariant increases in the attacker's relative strength, and in case (b) the expected number is increasing for all relative increases in the defender's strength. That is, the expected number of suicide operatives conditional on a suicide attack being launched increases as the conflict becomes more symmetric, according to the normalized relative strength of the attacker. The properties of the expected number of suicide operatives conditional on a suicide attack being launched are summarized in Corollary 3.

Corollary 3. In cases (a) and (b) of Theorem 1, the expected number of suicide operatives conditional on the attacker launching a suicide attack is: (i) decreasing with respect to the 
cost of each suicide operative, and (ii) increasing with respect to the two simple symmetry increasing transformations of the environment.

As highlighted above, the level of symmetry in the conflict, which depends on both the characteristics of the players and those of the weakest-link network, is a pivotal determinant of the optimal attack and defense strategies. In particular, note that in case (a) the attacker launches at most one attack and launches no attacks with positive probability. However, the probability that the attacker launches an attack is weakly increasing as the normalized relative strength of the attacker approaches unity (i.e., as the conflict becomes more symmetric). Thus, for both of the simple symmetry increasing transformations of the environment: (i) the probability of a terrorist event weakly increases, (ii) the conditional probability that such an event involves a suicide attack increases and (iii) the expected number of suicide operatives conditional on a suicide attack increases. Although the logic of this result is straightforward, this does complicate the conventional wisdom that an increase in the frequency and magnitude of terrorist attacks (of either the conventional or suicide variety) signals desperation on the part of a weakened terrorist organization. In particular, this popular characterization applies only in the case that the attacker has a normalized relative strength advantage. If the the attacker is disadvantaged with respect to his normalized relative strength, then an increase in the frequency and magnitude of terrorist attacks signals that the terrorist has actually become relatively stronger and the conflict has become more symmetric.

\section{Conclusion}

In this paper we examine a model of terrorism which focuses not on the rationality of suicide operatives, but on the tradeoffs facing a terrorist organization that has the ability to utilize either or both suicide terrorism tactics and conventional tactics. A second feature of our focus is weakest-link networks of targets and the structural asymmetries between attack and defense. In this context, we find that the attacker endogenously launches at most one attack. The attacker randomizes over exclusively using a conventional attack, exclusively using a suicide attack, and using a combination of a suicide attack and a conventional attack all with positive probability. Conditional on an attack being launched, the probability of a suicide attack depends on both the structural asymmetry arising in the weakest-link network and the asymmetry between the characteristics of both the attacker and the defender. Indeed, we

show that the strategic implications of asymmetry between terrorists and target governments cannot be fully captured by differences in available resources but must also take into account 
the technologies of attack and defense. The availability of suicide operatives acting against a weakest-link defense can lead to a previously unrecognized symmetrization of conflict. As the conflict becomes more symmetric, suicide attacks are more likely to occur, and, conditional on a suicide attack being launched, the expected number of suicide operatives is increasing.

This paper contributes to the analysis of the logic of suicide terrorism in finding that suicide operatives represent a discrete increase in terrorists' effective force that can symmetrize their conflict with target governments. This is particularly the case when governments are subject to a weakest-link defense technology (or definition of successful counterterror policy), as investigated here. Governments would do well by deemphasizing the importance of an individual attack and continuing with everyday life, as is often the case in Europe, whereas US policy continues to be cast in terms of publicly emphasizing terrorists' success. Under such a policy change extensions to our model that recognize alternative technologies and/or multiple terror attacks may come into play. 


\section{Appendix}

This appendix contains the proof of Theorem 1 and the statement of Theorem A.1, which provides an equilibrium in the remaining parameter configurations [i.e., the suicide attack technology is prohibitively costly for the attacker $\left(v_{A} \leq c\right)$ or the defender is so weak that suicide tactics are suboptimal for the attacker $\left.\left(\frac{v_{D}}{n}<c\right)\right]$.

Theorem A. 1. For the remaining parameter configurations a Nash equilibrium of the model of terrorism is for each player to allocate his forces as follows:

(c) If $\alpha<1$ and $v_{A} \leq c$, then for player $D$ and $\boldsymbol{x} \in\left[0, v_{A}\right]^{n}$,

$$
P_{D}(\boldsymbol{x})=\frac{\min _{i}\left\{x_{i}\right\}}{v_{A}}
$$

Similarly for player $A$ and $\hat{\boldsymbol{x}} \in\left[0, v_{A}\right]^{n}$,

$$
\hat{P}_{A}(\hat{\boldsymbol{x}})=1-\frac{n v_{A}}{v_{D}}+\frac{\sum_{i} \hat{x}_{i}}{v_{D}}
$$

The expected payoff for player $A$ is 0 , and the expected payoff for player $D$ is $v_{D}-n v_{A}$.

(d) If (i) $\alpha \geq 1$ and $\left(v_{D} / n\right)<c \leq S$, then for player $D$ and $\boldsymbol{x} \in\left[0,\left(v_{D} / n\right)\right]^{n}$,

$$
P_{D}(\boldsymbol{x})=1-\frac{v_{D}}{n v_{A}}+\frac{\min _{i}\left\{x_{i}\right\}}{v_{A}}
$$

Similarly for player $A$ and $\hat{\boldsymbol{x}} \in\left[0,\left(v_{D} / n\right)\right]^{n}$,

$$
\hat{P}_{A}(\hat{\boldsymbol{x}})=\frac{\sum_{i} \hat{x}_{i}}{v_{D}}
$$

The expected payoff for player $A$ is $v_{A}-\left(v_{D} / n\right)$, and the expected payoff for player $D$ is 0 .

\section{Proof of Theorem 1}

This proof, which is for case (a), shows that the pair of joint distribution functions $P_{D}$ and $\hat{P}_{A}$ form a Nash equilibrium in mixed strategies. In particular, we show that for each player each point in the support of their equilibrium $n$-variate distribution functions (stated in 
Theorem 1) results in the same expected payoff, and there are no profitable deviations from this support. The proofs of cases (b)-(d) following along similar lines.

We begin with the support of each player's case (a) equilibrium distribution of force. For $y_{k} \leq z_{k}$ for all $k=1,2, \ldots, n$, let $[\mathbf{y}, \mathbf{z}]$ denote the $n$-box $B=\left[y_{1}, z_{1}\right] \times\left[y_{2}, z_{2}\right] \times \ldots \times\left[y_{n}, z_{n}\right]$, the Cartesian product of $n$ closed intervals. The vertices of an $n$-box $B$ are the points $\left(v_{1}, v_{2}, \ldots, v_{n}\right)$ where $v_{k}$ is equal to $y_{k}$ or $z_{k}$. Recall the following two definitions.

Definition 4. Given an $n$-variate distribution $P$, the $P$-volume of the $n$-box $[\mathbf{y}, \mathbf{z}]$ is given by

$$
V_{P}([\mathbf{y}, \mathbf{z}])=\Delta_{y_{n}}^{z_{n}} \Delta_{y_{n-1}}^{z_{n-1}} \ldots \Delta_{y_{2}}^{z_{2}} \Delta_{y_{1}}^{z_{1}} P(\mathbf{t})
$$

where

$$
\Delta_{y_{k}}^{z_{k}} P(\mathbf{t})=P\left(t_{1}, \ldots, t_{k-1}, z_{k}, t_{k+1}, \ldots, t_{n}\right)-P\left(t_{1}, \ldots, t_{k-1}, y_{k}, t_{k+1}, \ldots, t_{n}\right)
$$

Definition 5. The support of an n-variate distribution function, $P$, is the complement of the union of all open sets of $\mathbb{R}^{n}$ with $P$-volume zero.

Given Definitions 4 and 5 it is straightforward to show that in all feasible case (a) parameter configurations the support of player D's equilibrium distribution of force is is uniformly distributed along the following set of line segments. ${ }^{11}$ One line segment connects the origin with the point $\mathbf{c} \equiv(c, c, \ldots, c)$. For $\mu=1, \ldots,\left\lfloor\frac{v_{A}}{c}\right\rfloor-1$ there are also line segments connecting the points $\mu \mathbf{S}$ to the point $\mu \mathbf{S}-\mathbf{c}$. If $v_{A}-c\left\lfloor\frac{v_{A}}{c}\right\rfloor>0$, then there is also a line segment that connects the point $\left\lfloor\frac{v_{A}}{c}\right\rfloor \mathbf{S}$ to the point $\mathbf{v}_{\mathbf{A}}-\left\lfloor\frac{v_{A}}{c}\right\rfloor(\mathbf{S}-\mathbf{c})$. Similarly, the support of player A's effective distribution of force consists of the combination of a set of mass points and mass uniformly distributed along a set of line segments both of which are located on the axes. One mass point of size $1-\frac{n\left(v_{a}+S-c\right)}{v_{D}}$ is located at the origin. On each axis $i$ there are $\left\lfloor\frac{v_{A}}{c}\right\rfloor$ mass points of size $\frac{S-c}{v_{D}}$ located at the points $\hat{x}_{i}=\mu S$ for $\mu=1, \ldots,\left\lfloor\frac{v_{A}}{c}\right\rfloor$. There is one line segment on each axis from the origin to the point $\hat{x}_{i}=c$. On each axis $i$ and for $\mu=1, \ldots,\left\lfloor\frac{v_{A}}{c}\right\rfloor-1$, there are also line segments from $\hat{x}_{i}=\mu S$ to $\hat{x}_{i}=\mu S+c$. If $v_{A}-c\left\lfloor\frac{v_{A}}{c}\right\rfloor>0$, then there is also a line segment on each axis $i$ from $\hat{x}_{i}=\left\lfloor\frac{v_{A}}{c}\right\rfloor S$ to $\hat{x}_{i}=v_{A}+\left\lfloor\frac{v_{A}}{c}\right\rfloor(S-c)$.

For each point in the support of player D's strategy, player D must have the same expected payoff. Let $\mathfrak{D}$ denote the set of $n$-tuples $\mathbf{x}$ such that $\tilde{\mu} S \leq x_{i} \leq \min \left\{\tilde{\mu} S+c, v_{A}+\left\lfloor\frac{v_{A}}{c}\right\rfloor(S-c)\right\}$

\footnotetext{
${ }^{11}$ Figure 1 shows that for $\left\lfloor\frac{v_{A}}{c}\right\rfloor=2$ and $n=2$ the support of player D's distribution of force $P_{D}$ is uniformly distributed along the three shaded line segments.
} 
for $\tilde{\mu}=0, \ldots,\left\lfloor\frac{v_{A}}{c}\right\rfloor$ and $i=1, \ldots, n$. Note that the support of player D's equilibrium strategy is a strict subset of $\mathfrak{D}$.

If player $A$ is using the equilibrium strategy $\hat{P}_{A}$ given in (2), then the expected payoff to player $D$ for any allocation of force $\mathbf{d} \in \mathbb{R}_{+}^{n}$ is

$$
\pi_{D}\left(\mathbf{x}, \hat{P}_{A}\right)=v_{D} \hat{P}_{A}(\mathbf{d})-\sum_{i} d_{i}
$$

From equation (2), the probability that with an allocation of $\mathbf{d}$ player $D$ wins every target $i$ is

$$
\hat{P}_{A}(\mathbf{d})=1-\frac{n\left(v_{A}+\left\lfloor\frac{v_{A}}{c}\right\rfloor(S-c)\right)}{v_{D}}+\frac{\sum_{i} h\left(d_{i}\right)}{v_{D}} .
$$

Inserting equation (12) into (11) and simplifying, the expected payoff to player $D$ from any allocation $\mathbf{d} \in \mathfrak{D}$, is $v_{D}-n\left(v_{A}+\left\lfloor\frac{v_{A}}{c}\right\rfloor(S-c)\right)$. Thus, as the support of player D's equilibrium strategy is contained in $\mathfrak{D}$, each point in the support of the $n$-variate distribution function $P_{D}$ results in the same expected payoff.

To show that there are no profitable deviations from this support, note that for $\tilde{\mu}=$ $0, \ldots,\left\lfloor\frac{v_{A}}{c}\right\rfloor$ it is clearly suboptimal for player $D$ to allocate a level of force $d_{i}$ to any target $i=1, \ldots, n$ such that $\min \left\{\tilde{\mu} S+c, v_{A}+\left\lfloor\frac{v_{A}}{c}\right\rfloor(S-c)\right\}<d_{i}<(\tilde{\mu}+1) S$. In any such allocation, player D could decrease his cost without changing his probability of winning all of the targets by setting $d_{i}=\min \left\{\tilde{\mu} S+c, v_{A}+\left\lfloor\frac{v_{A}}{c}\right\rfloor(S-c)\right\}$. That is, it is suboptimal for player $\mathrm{D}$ to allocate a level of force above $v_{A}+\left\lfloor\frac{v_{A}}{c}\right\rfloor(S-c)$ or to allocate a level of force between $\tilde{\mu} S+c$ and $(\tilde{\mu}+1) S$ to any target. However, this rules out all $n$-tuples in $\mathbb{R}_{+}^{n}-\mathfrak{D}$ from being profitable deviations. As established above all $n$-tuples in $\mathfrak{D}$ yield the same expected payoff. Thus, for player $\mathrm{D}$ there are no profitable deviations from the distribution of force $P_{D}$ given in (1).

The case of player $A$ is similar. For each point in the support of player A's strategy, player A must have the same expected payoff. Note that the support of $\hat{P}_{A}$ consists of all effective force allocations $\hat{\mathbf{a}} \in \mathbb{R}_{+}^{n}$ such that there exists exactly one target $i$ in which $\tilde{\mu} S \leq \hat{a}_{i} \leq \min \left\{\tilde{\mu} S+c, v_{A}+\left\lfloor\frac{v_{A}}{c}\right\rfloor(S-c)\right\}$ for $\tilde{\mu}=0, \ldots,\left\lfloor\frac{v_{A}}{c}\right\rfloor$ and $\hat{a}_{i^{\prime}}=0$ for all $i^{\prime} \neq i$. Clearly, it is cost minimizing for the attacker to set $s_{i}=\tilde{\mu}$. Thus, $\hat{a}_{i}=a_{i}+\tilde{\mu} S$ and, it follows that $0 \leq a_{i} \leq c$ for the one target that receives a positive level of effective force.

Given that player $D$ is using the equilibrium strategy $P_{D}$ given in (1) the expected payoff to player A from an effective force allocation $\hat{\mathbf{a}}$ from the support of $\hat{P}_{A}$ in which 
$\tilde{\mu} S \leq \hat{a}_{i} \leq \min \left\{\tilde{\mu} S+c, v_{A}+\left\lfloor\frac{v_{A}}{c}\right\rfloor(S-c)\right\}$ is

$$
\pi_{A}\left(\hat{\mathbf{a}}, P_{D}\right)=v_{A} P_{D}\left(\hat{a}_{i},\left\{v_{A}+\left\lfloor\frac{v_{A}}{c}\right\rfloor(S-c)\right\}_{i^{\prime} \neq i}\right)-\tilde{\mu} c-a_{i}
$$

where $P_{D}\left(\hat{a}_{i},\left\{v_{A}+\left\lfloor\frac{v_{A}}{c}\right\rfloor(S-c)\right\}_{i^{\prime} \neq i}\right)$ is the probability that player $A$ wins target $i$. Note that $P_{D}\left(\hat{a}_{i},\left\{v_{A}+\left\lfloor\frac{v_{A}}{c}\right\rfloor(S-c)\right\}_{i^{\prime} \neq i}\right)$ is the univariate marginal distribution of $P_{D}$ for the $i$ th target, which we will henceforth denote as $F_{D}^{i}$. From equation (1), it follows that for any effective force allocation in the support of $\hat{P}_{A}$ player A's expected payoff is

$$
\pi_{A}\left(\hat{\mathbf{a}}, P_{D}\right)=v_{A}\left(\frac{g\left(\hat{a}_{i}\right)}{v_{A}}\right)-\tilde{\mu} c-a_{i}=0
$$

as $g\left(\hat{a}_{i}\right)=a_{i}+\tilde{\mu} c$ for all such points.

We now show that there are no profitable deviations from the support of player $A$ 's equilibrium joint distribution. Note that if player A attacks only one target $i$, then it is clearly suboptimal for player $A$ to allocate a level of effective force $\hat{a}_{i}$ such that $\min \{\tilde{\mu} S+$ $\left.c, v_{A}+\left\lfloor\frac{v_{A}}{c}\right\rfloor(S-c)\right\}<\hat{a}_{i}<(\tilde{\mu}+1) S$. That is, it is clearly strictly dominated for player A to allocate an effective level of force above $v_{A}+\left\lfloor\frac{v_{A}}{c}\right\rfloor(S-c)$ or to allocate an effective level of force strictly between $\tilde{\mu} S+c$ and $(\tilde{\mu}+1) S$ to target $i$. The only remaining possible deviation from the support is for player $A$ to allocate a strictly positive level of effective force to two or more targets.

The probability that player $A$ wins both targets $i$ and $i^{\prime}$ is given by the bivariate marginal distribution $P_{D}\left(\hat{a}_{i}, \hat{a}_{i^{\prime}},\left\{v_{A}+\left\lfloor\frac{v_{A}}{c}\right\rfloor(S-c)\right\}_{i^{\prime \prime} \neq i, i^{\prime}}\right)$, which we will denote as $P_{D}^{i, i^{\prime}}\left(\hat{a}_{i}, \hat{a}_{i^{\prime}}\right)$. The expected payoff to player $A$ for any allocation of force $\hat{\mathbf{a}} \in \mathbb{R}_{+}^{n}$ which allocates a strictly positive level of force to two targets $i, i^{\prime}$ is

$$
\pi_{A}\left(\hat{\mathbf{a}}, P_{D}\right)=v_{A} F_{D}^{i}\left(\hat{a}_{i}\right)+v_{A} F_{D}^{i^{\prime}}\left(\hat{a}_{i^{\prime}}\right)-v_{A} P_{D}^{i, i^{\prime}}\left(\hat{a}_{i}, \hat{a}_{i^{\prime}}\right)-\left(a_{i}+c s_{i}\right)-\left(a_{i^{\prime}}+c s_{i^{\prime}}\right) .
$$

Simplifying,

$$
\pi_{A}\left(\hat{\mathbf{a}}, P_{D}\right) \leq-v_{A} P_{D}^{i, i^{\prime}}\left(\hat{a}_{i}, \hat{a}_{i^{\prime}}\right)<0
$$

where the left-hand weak inequality holds with equality if for $k=i, i^{\prime}$ there exist $\tilde{\mu}_{k} \in$ $\left[0, \ldots,\left\lfloor\frac{v_{A}}{c}\right\rfloor\right]$ such that $\hat{a}_{k} \in\left[\tilde{\mu}_{k} S, \min \left\{\tilde{\mu}_{k} S+c, v_{A}+\left\lfloor\frac{v_{A}}{c}\right\rfloor(S-c)\right]\right.$ and $\hat{a}_{k}=a_{k}+\tilde{\mu}_{k} S$. Furthermore, $P_{D}^{i, i^{\prime}}\left(\hat{a}_{i}, \hat{a}_{i^{\prime}}\right)>0$ as $\hat{a}_{i}, \hat{a}_{i^{\prime}}>0$, and thus it is unprofitable for player A to to allocate a strictly positive level of effective force to two targets.

The case of player $A$ allocating a strictly positive level of force to more than two targets follows directly. Clearly, in any optimal strategy player $A$ never allocates a strictly positive 
level of force to more than one target. This concludes the proof that in case (1) the pair of joint distribution functions $P_{D}$ and $\hat{P}_{A}$ constitute a Nash equilibrium of the model of terrorism with suicide attack. The proofs of cases (b)-(d) follow a similar line of argument. 


\section{References}

Arce, Daniel and Todd Sandler 2005. Counterterrorism: A Game Theoretic Approach. Journal of Conflict Resolution, 49(2) 183-200.

Atran, Scott 2003. Genesis of Suicide Terrorism. Science, 299(7 March) 1534-1539.

Azaiez, M. N., and Vicki M. Bier 2007. Optimal Resource Allocation for Security in Reliability Systems. European Journal of Operational Research, 181(2) 773-786.

Baye, Michael R., Dan Kovenock, and Casper G. de Vries 1996. The All-Pay Auction with Complete Information. Economic Theory, 8(2) 291-305.

Bier, Vicki M., and Vinod Abhichandani 2003. Optimal Allocation of Resources for Defense of Simple Series and Parallel Systems from Determined Adversaries. in: Risk-Based Decision Making in Water Resources X, American Society of Civil Engineers, Reston, VA, pp.59-76.

Bier, Vicki M., Aniruddha Nagaraj, and Vinod Abhichandani 2005. Protection of Simple Series and Parallel Systems with Components of Different Values. Reliability Engineering and System Safety, 87(3) 315-323.

Bier, Vicki M., Santiago Oliveros and Larry Samuelson 2007. Choosing What to Protect: Strategic Defensive Allocation against an Unknown Attacker. Journal of Public Economic Theory, 9(4) 563-587.

Borel, Emile 2001. La théorie du jeu les équations intégrales à noyau symétrique. Comptes Rendus de l'Académie 173, 1304-1308; English translation by Savage, Leonard J. 1953. The theory of play and integral equations with skew symmetric kernels. Econometrica 21(1), 97-100.

Clark, Derek J. and Kai A. Konrad 2007. Asymmetric Conflict: Weakest Link against Best Shot. Journal of Conflict Resolution, 51(3) 457-469.

Cornes, Richard 1993. Dyke Maintenance and Other Stories: Some Neglected Types of Public Goods. Quarterly Journal of Economics, 108(1) 259-271.

Crenshaw, Martha 2007. Explaining Suicide Terrorism: A Review Essay. Security Studies, 16(1) 133-162. 
Economist 2008. Special Report: Terrorism. The Economist, 19 July, 388(8595).

Franck, Raymond E. and Francois Melese 2004. Exploring the Structure of Terrorists' WMD Decisions: A Game Theory Approach. Defense 63 Security Analysis, 20(4) 355-372.

Gassebner, Martin, Richard Jong-A-Pin and Jochen O. Mierau 2008. Terrorism and Electoral Accountability: One Strike, You're Out! Economics Letters, 100(1) 125-129.

Golman, Russell and Scott E. Page 2008 General Blotto: Games of Strategic Allocative Mismatch. Public Choice, in press: doi:10.1007/s11127-008-9359-x

Gross, Oliver, and Robert Wagner 1950. A continuous Colonel Blotto game. RAND Corporation RM-408.

Hart, Sergiu 2008. Discrete Colonel Blotto and General Lotto Games. International Journal of Game Theory, 36(3-4) 441-460.

Hausken, Kjell 2002. Probabilistic Risk Analysis and Game Theory. Risk Analysis, 22(1) $17-27$.

Hausken, Kjell 2008. Strategic Defense and Attack for Series and Parallel Reliability Systems. European Journal of Operational Research, 186(2) 856-881.

Heal, Geoffrey and Howard Kunreuther 2005. IDS Models of Airline Security. Journal of Conflict Resolution, 49(2) 201-217.

Hirshleifer, Jack 1983. From Weakest-Link to Best-Shot: the Voluntary Provision of Public Goods. Public Choice, 41(3) 371-386.

Hoffman, Bruce and Gordon H. McCormick 2004. Terrorism, Signaling, and Suicide Attack. Studies in Conflict \& Terrorism, 27(4) 243-281.

King, Paul 2008. Editorial: The Mechanics of Terrorism. NATO Review, April.

Kovenock, Dan and Brian Roberson 2008. Terrorism and the Optimal Defense of Networks of Targets. Working Paper.

Kvasov, Dmitriy 2007. Contests with Limited Resources. Journal of Economic Theory, 136(1) 738-748. 
Iannaccone, Laurence R. 2006. The Market for Martyrs. Interdisciplinary Journal of Research on Religion, 2: Article 4.

Levitin, Gregory and Hanoch Ben-Haim 2007. Importance of Protection Against Intentional Attacks. Reliability Engineering and System Safety, 93(4) 639-646.

Roberson, Brian 2006. The Colonel Blotto Game. Economic Theory, 29(1) 1-24.

Roberson, Brian and Dmitriy Kvasov 2008. The Non-Constant-Sum Colonel Blotto Game. CESifo Working Paper No. 2378.

Rosenbaum, Thane 2008. The President Has Kept Us Safe. The Wall Street Journal, May 30 , p.A15.

Rosendorff, B. Peter and Todd Sandler 2004. Too much of a Good Thing? The Proactive Response Dilemma. Journal of Conflict Resolution, 48(5) 657-671.

Sageman, Marc 2004. Understanding Terror Networks, Philadelphia: University of Pennsylvania Press.

Sandler, Todd, Daniel Arce and Walter Enders 2008. Transnational Terrorism, Copenhagen Consensus 2008 Challenge Paper, www.copenhagenconsensus.com/Default.aspx?ID=1152.

US Congress 2002. Joint Inquiry into Intelligence Community Activities Before and After the Terrorist Attacks of September 11, 2001. Washington, DC: Senate Report No. 107-351, House Report No. 107-792. 


\section{CESifo Working Paper Series}

for full list see www.cesifo-group.org/wp

(address: Poschingerstr. 5, 81679 Munich, Germany, office@cesifo.de)

2689 Alexander Chudik, M. Hashem Pesaran and Elisa Tosetti, Weak and Strong Cross Section Dependence and Estimation of Large Panels, June 2009

2690 Mohamed El Hedi Arouri and Christophe Rault, On the Influence of Oil Prices on Stock Markets: Evidence from Panel Analysis in GCC Countries, June 2009

2691 Lars P. Feld and Christoph A. Schaltegger, Political Stability and Fiscal Policy - Time Series Evidence for the Swiss Federal Level since 1849, June 2009

2692 Michael Funke and Marc Gronwald, A Convex Hull Approach to Counterfactual Analysis of Trade Openness and Growth, June 2009

2693 Patricia Funk and Christina Gathmann, Does Direct Democracy Reduce the Size of Government? New Evidence from Historical Data, 1890-2000, June 2009

2694 Kirsten Wandschneider and Nikolaus Wolf, Shooting on a Moving Target: Explaining European Bank Rates during the Interwar Period, June 2009

2695 J. Atsu Amegashie, Third-Party Intervention in Conflicts and the Indirect Samaritan's Dilemma, June 2009

2696 Enrico Spolaore and Romain Wacziarg, War and Relatedness, June 2009

2697 Steven Brakman, Charles van Marrewijk and Arjen van Witteloostuijn, Market Liberalization in the European Natural Gas Market - the Importance of Capacity Constraints and Efficiency Differences, July 2009

2698 Huifang Tian, John Whalley and Yuezhou Cai, Trade Sanctions, Financial Transfers and BRIC's Participation in Global Climate Change Negotiations, July 2009

2699 Axel Dreher and Justina A. V. Fischer, Government Decentralization as a Disincentive for Transnational Terror? An Empirical Analysis, July 2009

2700 Balázs Égert, Tomasz Koźluk and Douglas Sutherland, Infrastructure and Growth: Empirical Evidence, July 2009

2701 Felix Bierbrauer, Optimal Income Taxation and Public Goods Provision in a Large Economy with Aggregate Uncertainty, July 2009

2702 Marc Gronwald, Investigating the U.S. Oil-Macroeconomy Nexus using Rolling Impulse Responses, July 2009

2703 Ali Bayar and Bram Smeets, Government Deficits in the European Union: An Analysis of Entry and Exit Dynamics, July 2009 
2704 Stergios Skaperdas, The Costs of Organized Violence: A Review of the Evidence, July 2009

2705 António Afonso and Christophe Rault, Spend-and-tax: A Panel Data Investigation for the EU, July 2009

2706 Bruno S. Frey, Punishment - and beyond, July 2009

2707 Michael Melvin and Mark P. Taylor, The Crisis in the Foreign Exchange Market, July 2009

2708 Firouz Gahvari, Friedman Rule in a Model with Endogenous Growth and Cash-inadvance Constraint, July 2009

2709 Jon H. Fiva and Gisle James Natvik, Do Re-election Probabilities Influence Public Investment?, July 2009

2710 Jarko Fidrmuc and Iikka Korhonen, The Impact of the Global Financial Crisis on Business Cycles in Asian Emerging Economies, July 2009

2711 J. Atsu Amegashie, Incomplete Property Rights and Overinvestment, July 2009

2712 Frank R. Lichtenberg, Response to Baker and Fugh-Berman's Critique of my Paper, "Why has Longevity Increased more in some States than in others?", July 2009

2713 Hans Jarle Kind, Tore Nilssen and Lars Sørgard, Business Models for Media Firms: Does Competition Matter for how they Raise Revenue?, July 2009

2714 Beatrix Brügger, Rafael Lalive and Josef Zweimüller, Does Culture Affect Unemployment? Evidence from the Röstigraben, July 2009

2715 Oliver Falck, Michael Fritsch and Stephan Heblich, Bohemians, Human Capital, and Regional Economic Growth, July 2009

2716 Wladimir Raymond, Pierre Mohnen, Franz Palm and Sybrand Schim van der Loeff, Innovative Sales, R\&D and Total Innovation Expenditures: Panel Evidence on their Dynamics, July 2009

2717 Ben J. Heijdra and Jochen O. Mierau, Annuity Market Imperfection, Retirement and Economic Growth, July 2009

2718 Kai Carstensen, Oliver Hülsewig and Timo Wollmershäuser, Price Dispersion in the Euro Area: The Case of a Symmetric Oil Price Shock, July 2009

2719 Katri Kosonen and Gaëtan Nicodème, The Role of Fiscal Instruments in Environmental Policy, July 2009

2720 Guglielmo Maria Caporale, Luca Onorante and Paolo Paesani, Inflation and Inflation Uncertainty in the Euro Area, July 2009 
2721 Thushyanthan Baskaran and Lars P. Feld, Fiscal Decentralization and Economic Growth in OECD Countries: Is there a Relationship?, July 2009

2722 Nadia Fiorino and Roberto Ricciuti, Interest Groups and Government Spending in Italy, 1876-1913, July 2009

2723 Andreas Wagener, Tax Competition, Relative Performance and Policy Imitation, July 2009

2724 Hans Fehr and Fabian Kindermann, Pension Funding and Individual Accounts in Economies with Life-cyclers and Myopes, July 2009

2725 Ernesto Reuben and Arno Riedl, Enforcement of Contribution Norms in Public Good Games with Heterogeneous Populations, July 2009

2726 Kurt Schmidheiny and Marius Brülhart, On the Equivalence of Location Choice Models: Conditional Logit, Nested Logit and Poisson, July 2009

2727 Bruno S. Frey, A Multiplicity of Approaches to Institutional Analysis. Applications to the Government and the Arts, July 2009

2728 Giovanni Villani, A Strategic R\&D Investment with Flexible Development Time in Real Option Game Analysis, July 2009

2729 Luca Di Corato and Michele Moretto, Investing in Biogas: Timing, Technological Choice and the Value of Flexibility from Inputs Mix, July 2009

2730 Gilad D. Aharonovitz, Nathan Skuza and Faysal Fahs, Can Integrity Replace Institutions? Theory and Evidence, July 2009

2731 Michele Moretto and Sergio Vergalli, Managing Migration through Conflicting Policies: an Option-theory Perspective, July 2009

2732 Volker Nitsch, Fly or Cry: Is Airport Noise Costly?, July 2009

2733 Francesco Cinnirella and Joachim Winter, Size Matters! Body Height and Labor Market Discrimination: A Cross-European Analysis, July 2009

2734 Samuel Bowles and Sandra Polanía Reyes, Economic Incentives and Social Preferences: A Preference-based Lucas Critique of Public Policy, July 2009

2735 Gary Burtless, Lessons of the Financial Crisis for the Design of National Pension Systems, July 2009

2736 Helmuth Cremer, Firouz Gahvari and Pierre Pestieau, Fertility, Human Capital Accumulation, and the Pension System, July 2009

2737 Hans Jarle Kind and Frank Stähler, Market Shares in Two-Sided Media Industries, July 2009 
2738 Pamela Campa, Alessandra Casarico and Paola Profeta, Gender Culture and Gender Gap in Employment, August 2009

2739 Sebastian Gechert, Supplementary Private Health Insurance in Selected Countries: Lessons for EU Governments?, August 2009

2740 Leif Danziger, Endogenous Monopsony and the Perverse Effect of the Minimum Wage in Small Firms, August 2009

2741 Yan Dong and John Whalley, A Third Benefit of Joint Non-OPEC Carbon Taxes: Transferring OPEC Monopoly Rent, August 2009

2742 Valentina Bosetti, Carlo Carraro and Massimo Tavoni, Climate Change Mitigation Strategies in Fast-Growing Countries: The Benefits of Early Action, August 2009

2743 Christina Felfe, The Willingness to Pay for Job Amenities: Evidence from Mothers' Return to Work, August 2009

2744 Jörg Franke, Christian Kanzow, Wolfgang Leininger and Alexandra Väth, Effort Maximization in Asymmetric N-Person Contest Games, August 2009

2745 Bruno S. Frey and Paolo Pamini, Making World Heritage Truly Global: The Culture Certificate Scheme, August 2009

2746 Frank N. Caliendo, Is Social Security behind the Collapse of Personal Saving?, August 2009

2747 Caterina Liesegang and Marco Runkel, Corporate Income Taxation of Multinationals and Fiscal Equalization, August 2009

2748 Chrysovalantou Milliou and Apostolis Pavlou, Upstream Horizontal Mergers and Efficiency Gains, August 2009

2749 Rüdiger Pethig and Christian Wittlich, Interaction of Carbon Reduction and Green Energy Promotion in a Small Fossil-Fuel Importing Economy, August 2009

2750 Kai Carstensen, Oliver Hülsewig and Timo Wollmershäuser, Monetary Policy Transmission and House Prices: European Cross-country Evidence, August 2009

2751 Olaf Posch, Explaining Output Volatility: The Case of Taxation, August 2009

2752 Beatrice Scheubel, Daniel Schunk and Joachim Winter, Don't Raise the Retirement Age! An Experiment on Opposition to Pension Reforms and East-West Differences in Germany, August 2009

2753 Daniel G. Arce, Dan Kovenock and Brian Roberson, Suicide Terrorism and the Weakest Link, August 2009 